المجلد (12) العدد (2) (20)

2020 لسنة
المجلة العراقية

لبحوث السوق وحماية المستهملك

DOI: $\underline{\text { http://dx.doi.org/10.28936/jmracpc12.2.2020.(2) }}$

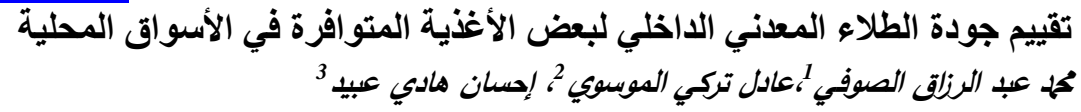

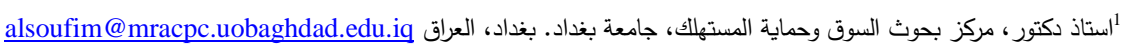

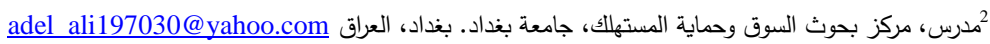

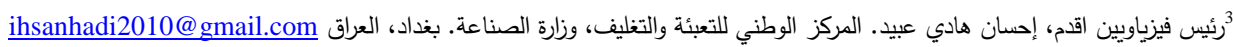

الاستلام 16/12/ 2019، القبول 15/3/3 2020، النشر /312 2020

CCBY 4.0 https://creativecommons.org/licenses/by/4.0ع العمل تحت سياسية ترخيص من نوع

الخلاصة

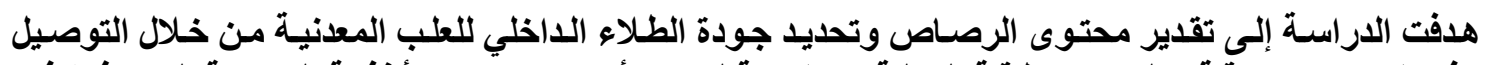

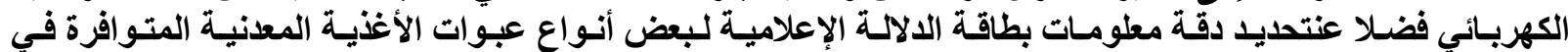

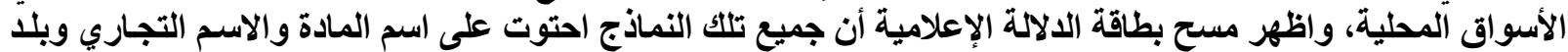

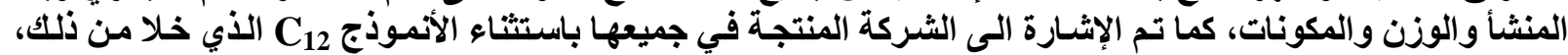

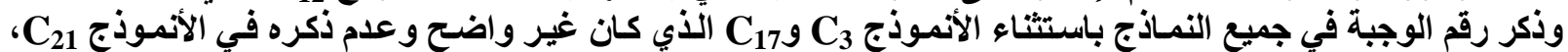

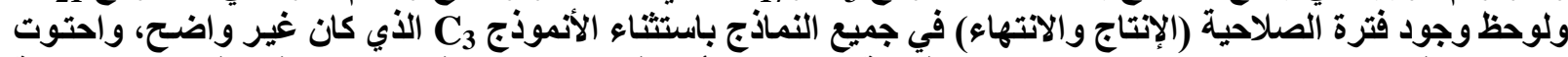

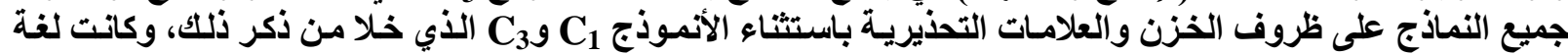

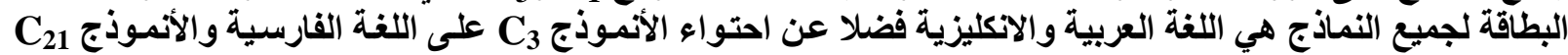

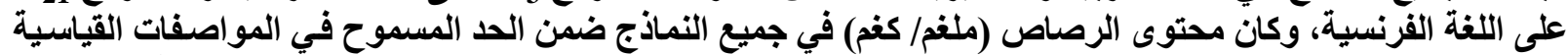

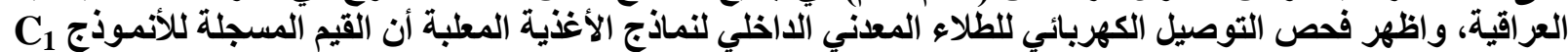

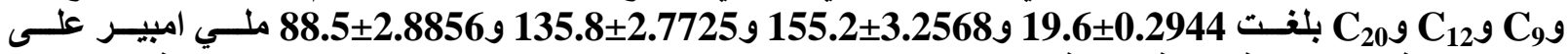

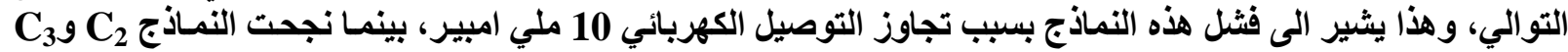

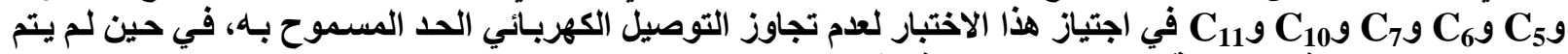

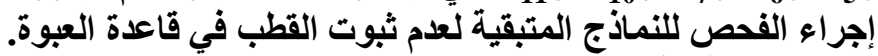

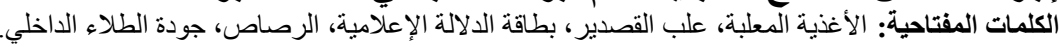

DOI: http://dx.doi.org/10.28936/jmracpc12.2.2020.(2)

\title{
QUALITY EVALUATION OF THE INTERNAL METALLIC COATING FOR SOME FOODS THAT AVAILABLE IN THE LOCAL MARKETS
}

Mohammed A. Alsoufi ${ }^{1}$, Adil. T. Al-Mousawi ${ }^{2}$, IhsanHadi Obaid ${ }^{3}$

${ }^{1}$ Market Research and ConsumerProtectionCenter, University of Baghdad, Iraqalsoufim@ mracpc.uobaghdad.edu.iq

${ }^{2}$ Market Research and ConsumerProtectionCenter, University of Baghdad, Iraqadel ali197030@yahoo.com

${ }^{3}$ NationalCenter for Packing and Packaging, Ministry of Industry and Minerals, Baghdad, Iraqihsanhadi2010@gmail.com

Received 16/ 12/ 2019, Accepted 15/3/ 2020, Published 31/ 12/ 2020

This work is licensed under a CCBY 4.0 https://creativecommons.org/licenses/by/4.0

\section{ABSTRACT}

The study aimed to estimate the content of lead and determine the quality of the internal coating of metal cans through electrical conductivity as well as to determine the accuracy of the information card for some types of canned food that available in local markets. The information card test showed that all of these samples contained the name 
المجلد (12) العدد (2)

2020 لسنة

\section{المجلة العراقية \\ لبحوث السوق وحماية المستهملك}

of the food, trade mark, country origin, weight, and components, as was indicated by the company producing in all of them except for the $C_{12}$ sample which was otherwise, and the batch number was mentioned in all samples except for the $C_{3}$ and $C_{17}$ which was not clear and not mentioned in the $\mathrm{C}_{21}$, and the validity period was observed (produce and finish) in all samples except for the $C_{3}$, which was not clear, and all the samples contained storage conditions and warning signs except for the $C_{1}$ and $C_{3}$ that were not mentioned, and the language of the card for all models was Arabic and English as well as the $\mathbf{C}_{3}$ form contained the Persian language and the form $\mathrm{C}_{21}$ on the French language. The lead content $(\mathrm{mg} / \mathrm{kg}$ ) in all samples was within the permissible limit in the Iraqi standard specifications, and the examination of the electrical conductivity of the internal metallic coating of canned food samples showed that the recorded values for the form $C_{1}, C_{9}, C_{12}$ and $\mathrm{C}_{20}$ were $19.6 \pm 0.2944,155.2 \pm 3.2568,135.8 \pm 2.7725$ and $88.5 \pm 2.8856 \mathrm{~mA}$ respectively, and this indicates the failure of these samples due to the electrical conductivity exceeding $10 \mathrm{~mA}$, while the $C_{2}, C_{3}, C_{5}, C_{6}, C_{7}, C_{10}$ and $C_{11}$ samples succeeded in passing this test because the electrical conductivity did not exceed the permissible limit, while no examination of the remaining models for failure to fix the electrode at the base of the package.

Keywords: canned food, tin cans, informational label, lead, interior paint quality.

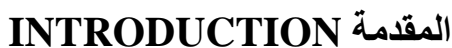

بمثل استهلاك الأغذية المعلبة أحد أكثر أنماط الاستهلاك تطور العان على مستوى العالم، والتي لاقت إقبالا و اسعا عليها

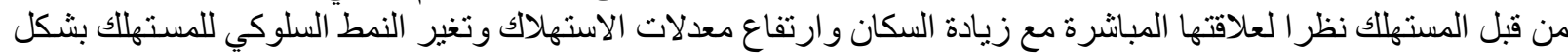

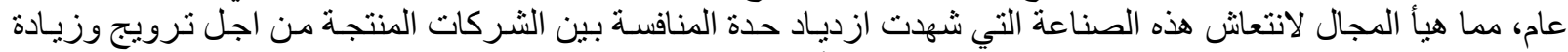
تسويق منتجاتها (Al-Hamadani et al., 2014)، إذ بدأت هذه الصناعة بالظهور بشكل ملاحظ على الإنى المستوى التجاري التجاري

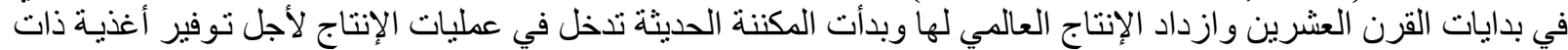

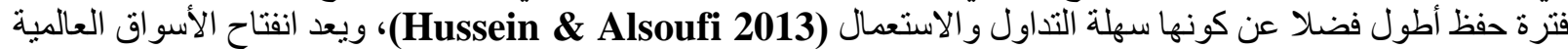

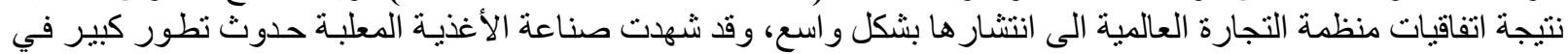

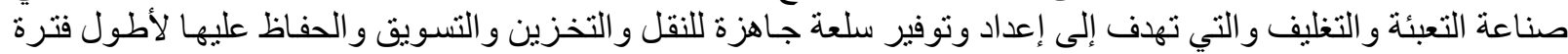

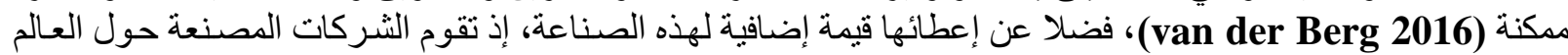

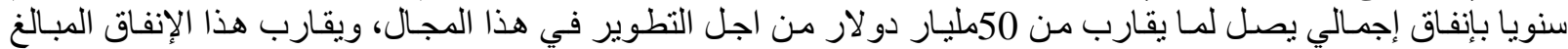

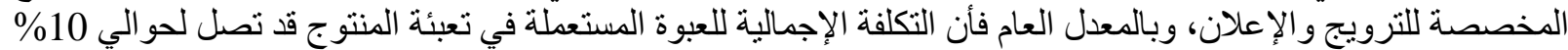

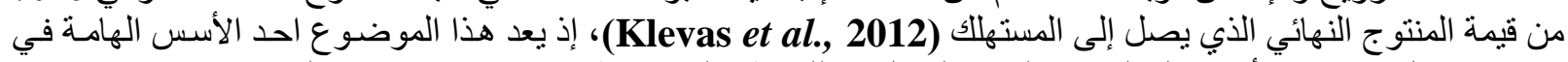

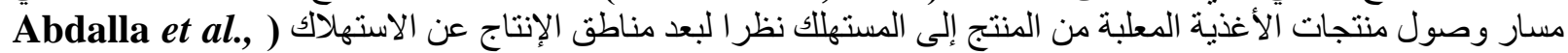

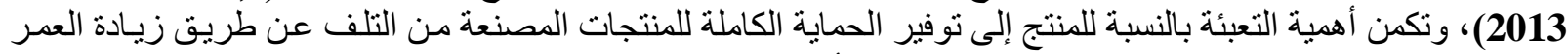

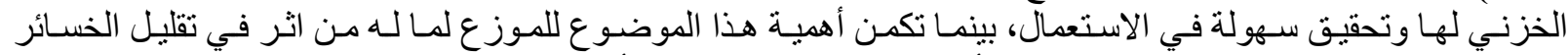

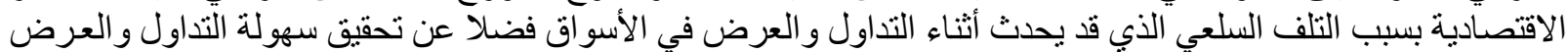

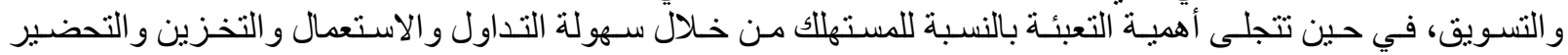

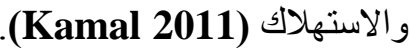

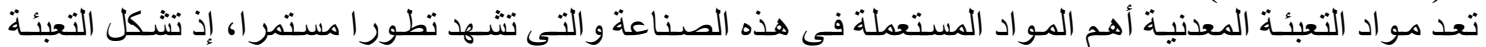

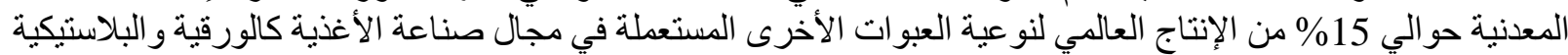

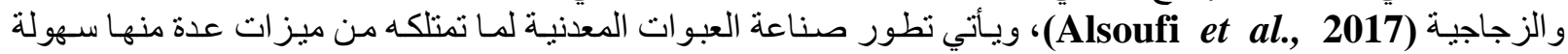

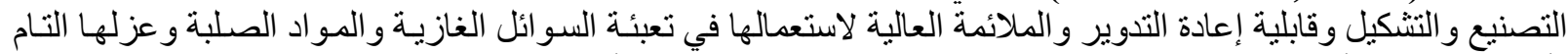

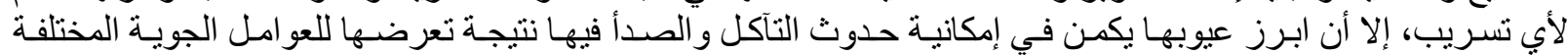

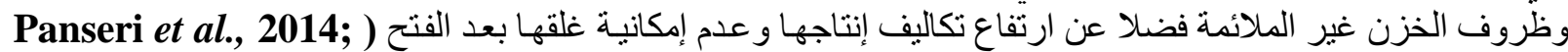

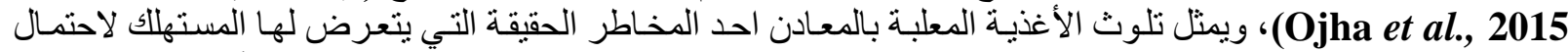

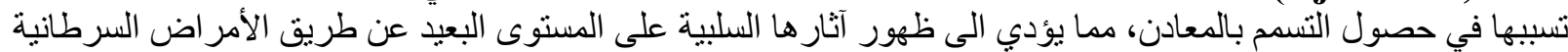

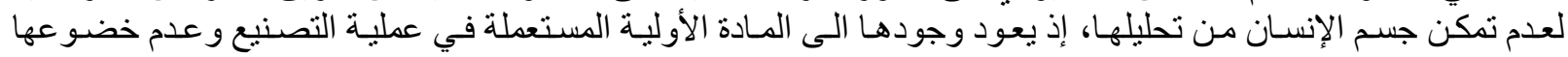


المجلد (12) العدد (2) (12)

2020 لسنة
المجلة العراقية

لبحوث السوق ومماية المستتملك

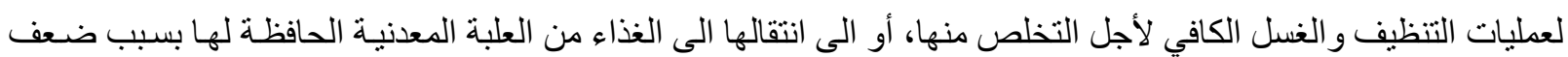

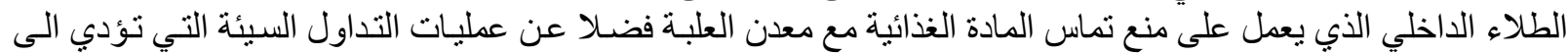

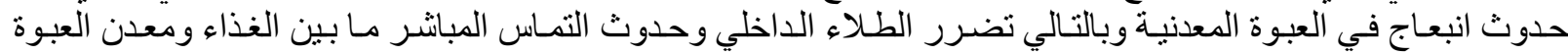
(Aycicek et al., 2008; Rajaganapthy et al., 2011; Al-Hamadani et al., 2014)

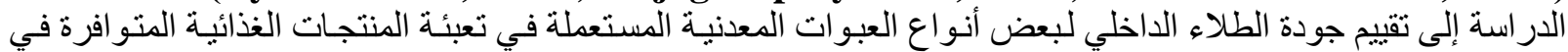

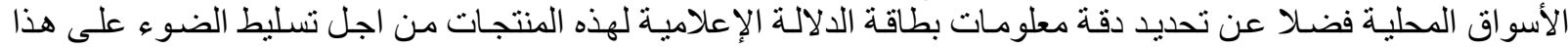

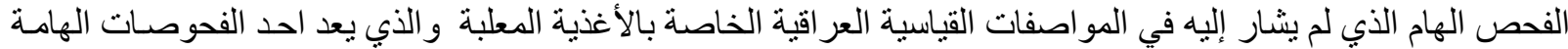
التي تبين سلامة الغذاء المعلب.

المواد وطرائق العمل MATERIALS AND METHODS

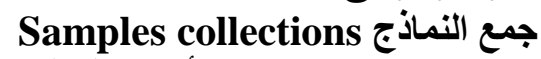
جمعت نمـاذج الأغذيـة المعلبـة ذات المناثـئ المختلفة خـلال الفترة الممتـدة من 1 الى 30 آيـار لسنة 2019 مـن الأسو اق المحلية في مدينة بغداد.

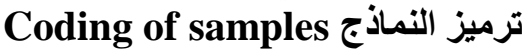

رمزت نماذج الأغذية المعلبة وفقا لما مبين في (الجدول، 1).

جدول (1): تصنيف وترميز نماذج الأغذية المعلبة المستحصل عليها من الأسواق المحلية.

\begin{tabular}{|c|c|c|c|}
\hline الزمز & اسم المنتوج التجاري & 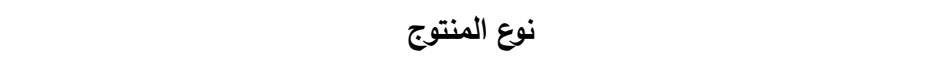 & ت \\
\hline $\mathrm{C}_{1}$ & Amazon أمازون & شرائح أناناس في محلول سكري Pineapple & 1 \\
\hline $\mathrm{C}_{2}$ & Almotamayez المتميز & شرائح أناناس في شراب خفيف Pineapple in Light Syrup & 2 \\
\hline $\mathrm{C}_{3}$ & بدرام Pedram & Temato Paste معون طماطم & 3 \\
\hline $\mathrm{C}_{4}$ & الفخر Al-Fkhar & Tomato Paste معجون طماطم & 4 \\
\hline $\mathrm{C}_{5}$ & زلوم Zalloum & Tعجون طماطم Tomato Paste & 5 \\
\hline $\mathrm{C}_{6}$ & زلوم Zalloum & Green Peas \& Carrots بازيلا وجزر & 6 \\
\hline $\mathrm{C}_{7}$ & الفخر Al-Fkhar & حمص حب Chick Peas & 7 \\
\hline $\mathrm{C}_{8}$ & Green Valley السهل الاخضر & حص حب Chick Peas & 8 \\
\hline $\mathrm{C}_{9}$ & Green Valley السهل الاخضر & فول مدمس Medammes (Broad Beans) & 9 \\
\hline $\mathrm{C}_{10}$ & ريفانا Revana & Green Peas بازيلا خضراء & 10 \\
\hline $\mathrm{C}_{11}$ & Revana ريفانا & Foul Medamasa فول مدمس & 11 \\
\hline $\mathrm{C}_{12}$ & حدائق بلدي Baladee Gardens & بازيلا وجزر Peas \& Carrots & 12 \\
\hline $\mathrm{C}_{13}$ & درة Durra & Green Peas بازلاء خضراء & 13 \\
\hline $\mathrm{C}_{14}$ & سمايل & Pبنة تشدر مطبوخة Processed Cheddar Cheese & 14 \\
\hline $\mathrm{C}_{15}$ & Bega بيغا & جبن مطبوخ Processed Cheese & 15 \\
\hline $\mathrm{C}_{16}$ & 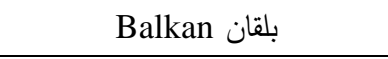 & جبنة الثيدر Cheddar Cheese & 16 \\
\hline $\mathrm{C}_{17}$ & كرافت Kraft & Pبنة تشيدر مطبوخة Processed Cheddar Cheese & 17 \\
\hline $\mathrm{C}_{18}$ & هاجدو Hajdu & Pبنة تشيدر مطبوخة ومبسترة Processed and Pasteurized Cheddar Cheese & 18 \\
\hline $\mathrm{C}_{19}$ & Happy Cow البقرة السعيدة & جبنة نمساوية مصنعة Austrian Processed Cheese & 19 \\
\hline $\mathrm{C}_{20}$ & سنيور Senior & فطر (مقطع ومسلوق) Mushrooms (Pieces \& Stems) & 20 \\
\hline $\mathrm{C}_{21}$ & فونتيFounty & سردين مطبوخ بالزيت النباتي Sardines in Vegetable Oil & 21 \\
\hline
\end{tabular}


المجلد (12) العدد (2) (12)

2020 لسنة
المجلة العراقية

لبحوث السوق وحماية المستهملك

Information card بطاقة الدلالة الإعلامية

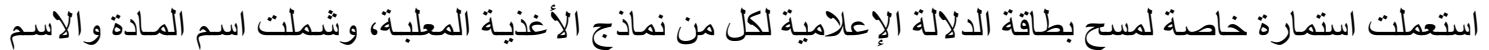

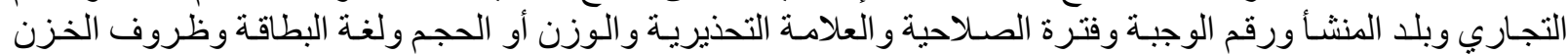

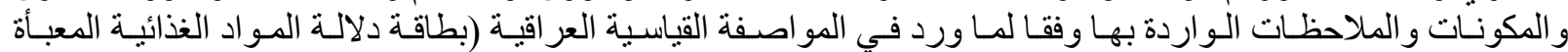

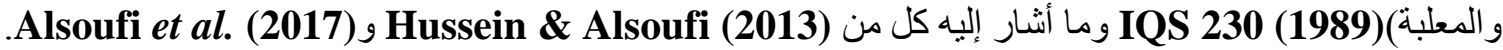

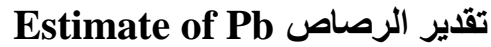

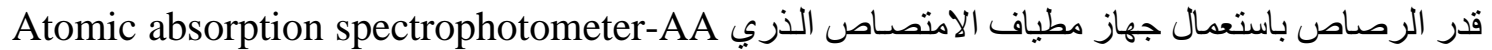

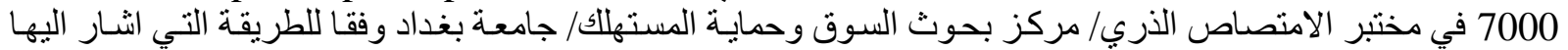

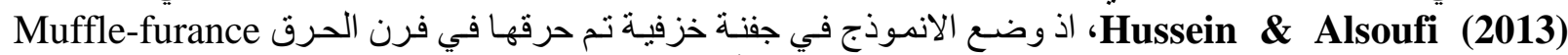

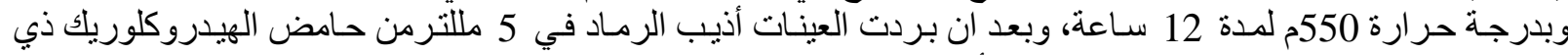
تركيز\%20\%، بعدها رشح المحلول باستعمال أور اق الترشيح (Wattman No. 1) وخفف إلى حجم 50 مللتر باستعمال الماء المقطر.

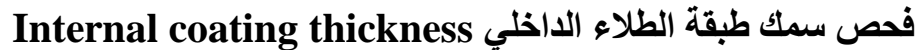

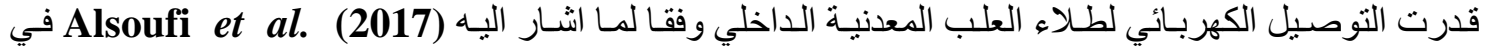

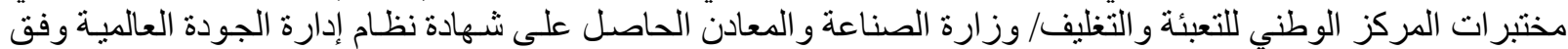

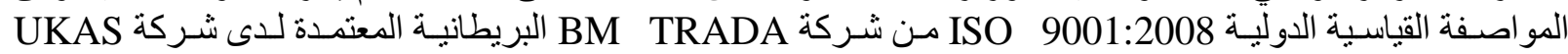

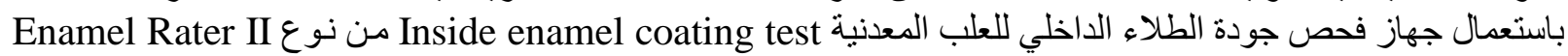

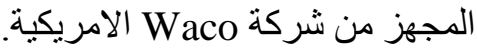

\section{RESULTS AND DISCUSSION النتائج والمناقشة Information card test مسح بطاقة الدالة الإعلامية}

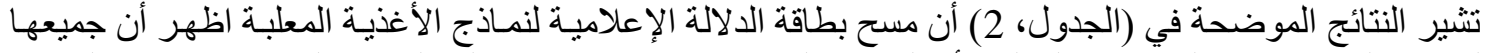

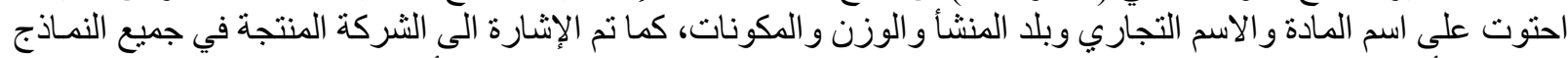

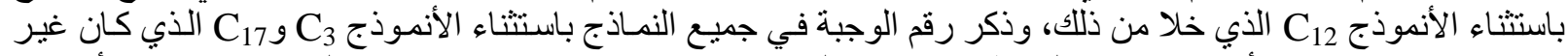

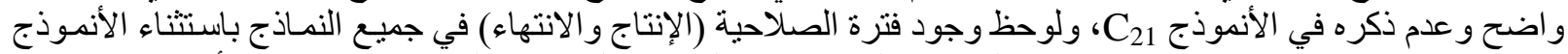

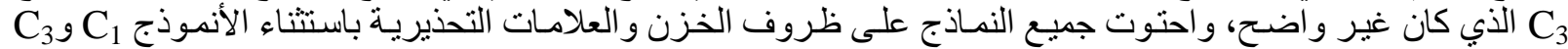

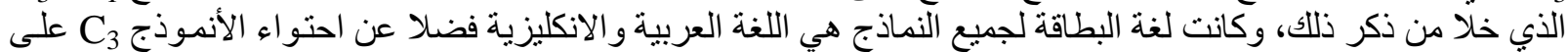

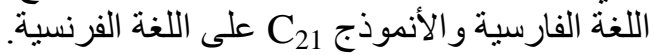

جدول (2): مسح معلومات بطاقة الدلالة الإعلامية لنماذج الأغذية المعلبة.

\begin{tabular}{|c|c|c|c|c|c|c|c|c|c|c|c|}
\hline \multirow[b]{2}{*}{ المكونات } & \multirow[b]{2}{*}{ لغة البطاقة } & \multirow{2}{*}{ المزن } & \multirow{2}{*}{ والعلامة التحذيرية } & \multicolumn{2}{|c|}{ فترة الصلاحية } & \multirow[b]{2}{*}{ رقم الوجبة } & \multirow[b]{2}{*}{ الشركة المنتجة } & \multirow[b]{2}{*}{ بلد المنشأ } & \multirow[b]{2}{*}{ الاسم التجاري } & \multirow[b]{2}{*}{ اسم المادة } & \multirow[b]{2}{*}{ الزمز } \\
\hline & & & & الانتهاء & الإنتاج & & & & & & \\
\hline مذكورة & $\begin{array}{l}\text { العربية والإنكليزية } \\
\text { Arabic \& } \\
\text { English }\end{array}$ & 565 & $\begin{array}{l}\text { لا يوجد } \\
\text { Non }\end{array}$ & $\begin{array}{c}10 / 201 \\
9\end{array}$ & $\begin{array}{c}10 / 201 \\
7\end{array}$ & $\begin{array}{c}\text { U117BSL } \\
\text { P7B272 } \\
17: 04\end{array}$ & $\begin{array}{l}\text { Prime Products } \\
\text { Industry CO.,LTD }\end{array}$ & $\begin{array}{c}\text { تايلند } \\
\text { Thailand }\end{array}$ & $\begin{array}{c}\text { ازمازون } \\
\text { Amazon }\end{array}$ & $\begin{array}{l}\text { شرائح أناناس في } 2 \text { سكري } \\
\text { Pineapple }\end{array}$ & $\mathbf{C}_{1}$ \\
\hline مذكورة & $\begin{array}{l}\text { العربية والإنكليزية } \\
\text { Arabic \& } \\
\text { English }\end{array}$ & 565 & $\begin{array}{c}\text { تحفظ المحتويات في البراد بعد } \\
\text { Keep refrigerated after } \\
\text { opening }\end{array}$ & $\begin{array}{c}30 / 11 / 2 \\
019\end{array}$ & $\begin{array}{c}1 / 12 / 2 \\
017\end{array}$ & $\begin{array}{l}\text { U8SSL } \\
\text { P7B435 } \\
16: 19\end{array}$ & $\begin{array}{l}\text { Canned Food } \\
\text { PTE LTD. }\end{array}$ & $\begin{array}{c}\text { تايلند } \\
\text { Thailand }\end{array}$ & $\begin{array}{c}\text { Almotamay } \\
\text { ez }\end{array}$ & $\begin{array}{c}\text { شرائح أناناس في شراب } \\
\text { خineapple in } \\
\text { Light Syrup }\end{array}$ & $\mathrm{C}_{2}$ \\
\hline مذكورة & الفارسية والعربية & $350 \pm 10$ & $\begin{array}{l}\text { لا يوجد } \\
\text { Non }\end{array}$ & غير واضح & غير & غير واضح & $\begin{array}{c}\text { Pedram Mashhad } \\
\text { Co }\end{array}$ & $\begin{array}{l}\text { ايران } \\
\text { Iran }\end{array}$ & $\begin{array}{c}\text { بدرام } \\
\text { Pedram }\end{array}$ & $\begin{array}{l}\text { معجون طماطم } \\
\text { Tomato Paste }\end{array}$ & $\mathbf{C}_{3}$ \\
\hline مذكورة & $\begin{array}{l}\text { العربية والإنكليزية } \\
\text { Arabic \& } \\
\text { English }\end{array}$ & 400 & $\begin{array}{c}\text { تاريخ الإنتاج والانتهاء انظر الى الى الأسفل } \\
\text { Date of Production and } \\
\text { Expiry: See Top/Bottom }\end{array}$ & $\begin{array}{c}06 / 01 / 2 \\
021\end{array}$ & $\begin{array}{c}07 / 01 / \\
2019\end{array}$ & $\begin{array}{c}\text { B:TM } 007 \\
09: 13 \\
\text { TN 20:32 }\end{array}$ & $\begin{array}{l}\text { Universal } \\
\text { Industries } \\
\text { CO.LTD. }\end{array}$ & $\begin{array}{c}\text { الاردن } \\
\text { Jordan }\end{array}$ & زلوم & $\begin{array}{c}\text { معون طماطم } \\
\text { Tomato Paste }\end{array}$ & $\mathbf{C}_{4}$ \\
\hline
\end{tabular}


المجلد (12) العدد (2) لسنة 2020
المجلة العراقية

لبحوث السوق وحماية المستتملك

\begin{tabular}{|c|c|c|c|c|c|c|c|c|c|c|c|}
\hline مذكورة & $\begin{array}{c}\text { العربية والإكليزية } \\
\text { Arabic } \\
\text { \&Engilsh }\end{array}$ & 400 & 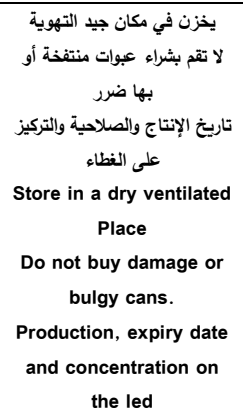 & $\begin{array}{c}08 / 01 / 2 \\
020\end{array}$ & $\begin{array}{c}09 / 07 / \\
2018\end{array}$ & $\begin{array}{c}1807-015 \\
01: 57: 24\end{array}$ & $\begin{array}{l}\text { Fal Food } \\
\text { Industries }\end{array}$ & $\begin{array}{l}\text { السعودية } \\
\text { K.S.A }\end{array}$ & $\begin{array}{c}\text { الفخر } \\
\text { Al-Fkhar }\end{array}$ & $\begin{array}{c}\text { معجون طماطم } \\
\text { Tomato Paste }\end{array}$ & $\mathbf{C}_{5}$ \\
\hline مذكورة & $\begin{array}{c}\text { العربية والإكليزية } \\
\text { Arabic \& } \\
\text { English }\end{array}$ & 400 & 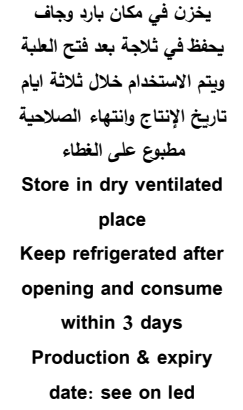 & $\begin{array}{c}02 / 08 / 2 \\
019\end{array}$ & $\begin{array}{c}03 / 02 / \\
2018\end{array}$ & $\begin{array}{c}\text { C } 05: 26 \\
1802-034\end{array}$ & $\begin{array}{l}\text { Al-wedyan } \\
\text { National Co For } \\
\text { Food Products }\end{array}$ & $\begin{array}{l}\text { السعودية } \\
\text { K.S.A }\end{array}$ & Al-Fkhar & $\begin{array}{c}\text { حمص حب } \\
\text { Chick Peas }\end{array}$ & $\mathrm{C}_{6}$ \\
\hline مذكورة & $\begin{array}{c}\text { العربية والإنكليزية } \\
\text { Arabic \& } \\
\text { English }\end{array}$ & 400 & $\begin{array}{c}\text { تاريخ الإنتاج والانتهاء مدون } \\
\text { على العلبة } \\
\text { Packing date:/ expiry } \\
\text { date: see led }\end{array}$ & $\begin{array}{c}14 / 06 / 2 \\
019\end{array}$ & $\begin{array}{c}15 / 12 / \\
2017\end{array}$ & $\begin{array}{c}4200 / 0105 \\
7 \\
84918 \mathrm{P}\end{array}$ & $\begin{array}{l}\text { Zigui County } \\
\text { Quga Food } \\
\text { Co.,LTD }\end{array}$ & $\begin{array}{l}\text { الصين } \\
\text { China }\end{array}$ & GreenValley & $\begin{array}{c}\text { حصص حب } \\
\text { Chick Peas }\end{array}$ & $\mathbf{C}_{7}$ \\
\hline مذكورة & $\begin{array}{c}\text { العربية والإنكليزية } \\
\text { Arabic \& } \\
\text { English }\end{array}$ & 380 & 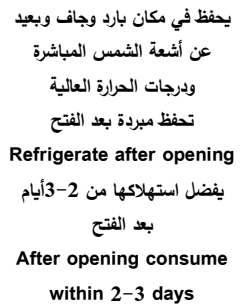 & $\begin{array}{c}31 / 01 / 2 \\
020\end{array}$ & $\begin{array}{c}01 / 08 / \\
2018\end{array}$ & $\begin{array}{c}\text { B:GP } 154 \\
\text { GP } 16: 52 \\
19: 37\end{array}$ & شركة الصناعات الدولية & $\begin{array}{c}\text { الاردن } \\
\text { Jordan }\end{array}$ & $\begin{array}{c}\text { ريفانا } \\
\text { Revana }\end{array}$ & $\begin{array}{c}\text { بازيلا خضراء } \\
\text { Green Peas }\end{array}$ & $\mathbf{C}_{8}$ \\
\hline مذكورة & $\begin{array}{c}\text { العربية والإنكليزية } \\
\text { Arabic \& } \\
\text { English }\end{array}$ & 380 & 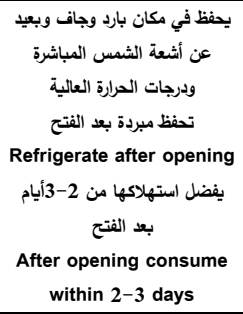 & $\begin{array}{c}12 / 03 / 2 \\
020\end{array}$ & $\begin{array}{c}13 / 09 / \\
2018\end{array}$ & $\begin{array}{c}\text { FF } 181 \\
\text { FF 12:39 } \\
14: 50\end{array}$ & شركة الصناعات الدولية & $\begin{array}{c}\text { الاردن } \\
\text { Jordan }\end{array}$ & $\begin{array}{c}\text { ريفانا } \\
\text { Revana }\end{array}$ & $\begin{array}{c}\text { فول مدمس } \\
\text { Foul Medamasa }\end{array}$ & $\mathrm{C}_{9}$ \\
\hline مذكورة & $\begin{array}{c}\text { العربية والإكليزية } \\
\text { Arabic \& } \\
\text { English }\end{array}$ & 400 & 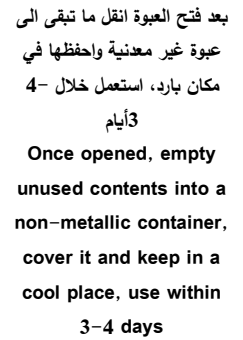 & $\begin{array}{c}29 / 04 / 2 \\
019\end{array}$ & $\begin{array}{c}30 / 10 / \\
2017\end{array}$ & $\begin{array}{c}4200 / 0105 \\
7 \\
82219 P\end{array}$ & $\begin{array}{l}\text { YichangZigui } \\
\text { County Quga } \\
\text { Food Co.,LTD }\end{array}$ & $\begin{array}{l}\text { الصين } \\
\text { China }\end{array}$ & GreenValley & $\begin{array}{c}\text { فول مدمس } \\
\text { Medammes } \\
\text { (Broad Beans) }\end{array}$ & $\mathrm{C}_{10}$ \\
\hline
\end{tabular}


المجلد (12) العدد (2)

لسنـة 2020
المجلة العراقية

لبحوث السوق وحماية المستهملك

\begin{tabular}{|c|c|c|c|c|c|c|c|c|c|c|c|}
\hline مذكورة & $\begin{array}{c}\text { العربية والإنكليزية } \\
\text { Arabic \& } \\
\text { English }\end{array}$ & 400 & 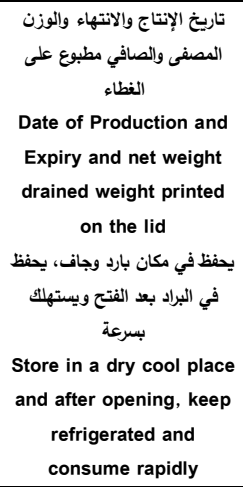 & $\begin{array}{c}29 / 07 / 2 \\
020\end{array}$ & $\begin{array}{c}30 / 01 / \\
2019\end{array}$ & $\begin{array}{l}\text { B:GPG } 017 \\
\text { 08:02 } \\
\text { GPG 17:54 }\end{array}$ & $\begin{array}{l}\text { Universal } \\
\text { Industries } \\
\text { CO.LTD. }\end{array}$ & $\begin{array}{l}\text { الاردن } \\
\text { Jordan }\end{array}$ & Zalloum & $\begin{array}{c}\text { بازيلا وجزر } \\
\text { Green Peas \& } \\
\text { Carrots }\end{array}$ & $\mathbf{C}_{11}$ \\
\hline مذكورة & $\begin{array}{c}\text { العربية والإنكليزية } \\
\text { Arabic \& } \\
\text { English }\end{array}$ & 400 & $\begin{array}{c}\text { يحفظ في مكان بارد وجاف } \\
\text { Keep in a cool and dry } \\
\text { place }\end{array}$ & $\begin{array}{c}27 / 10 / 2 \\
019\end{array}$ & $\begin{array}{c}28 / 04 / \\
2018\end{array}$ & $\begin{array}{c}3200 / 0112 \\
2 \\
67 P 894\end{array}$ & $\begin{array}{c}\text { غير مذكور } \\
\text { Not found }\end{array}$ & $\begin{array}{l}\text { الصين } \\
\text { China }\end{array}$ & $\begin{array}{l}\text { حدائق بلدي } \\
\text { BaladeeGar } \\
\quad \text { dens }\end{array}$ & $\begin{array}{c}\text { بازيلا وجزر \& Carrots } \\
\text { Peas \& }\end{array}$ & $\mathbf{C}_{12}$ \\
\hline مذكورة & $\begin{array}{c}\text { العربية والإنكليزية } \\
\text { Arabic \& } \\
\text { English }\end{array}$ & 400 & $\begin{array}{c}\text { عند فتح العلبة تحفظ في الثلاجة خلال يومين } \\
\text { وتلخدم } \\
\text { Once opened keep } \\
\text { refrigerated and use } \\
\text { within } 2 \text { days }\end{array}$ & $\begin{array}{c}19 / 04 / 2 \\
019\end{array}$ & $\begin{array}{c}20 / 10 / \\
2017\end{array}$ & $\begin{array}{c}4200 / 01 \\
057 \\
80128 P\end{array}$ & $\begin{array}{l}\text { Zigui Country } \\
\text { Qugu Food } \\
\text { Co.,LTD }\end{array}$ & $\begin{array}{l}\text { الصين } \\
\text { China }\end{array}$ & $\begin{array}{c}\text { درة } \\
\text { Durra }\end{array}$ & $\begin{array}{c}\text { بازلاء خضراء } \\
\text { Green Peas }\end{array}$ & $\mathbf{C}_{13}$ \\
\hline مذكورة & $\begin{array}{l}\text { العربية والإنكليزية } \\
\text { Arabic \& } \\
\text { English }\end{array}$ & 113 & 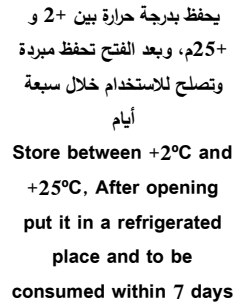 & $\begin{array}{c}03 / 12 / 2 \\
020\end{array}$ & $\begin{array}{c}04 / 12 / \\
2018\end{array}$ & $\begin{array}{c}\text { B8 } 348 \\
\text { KON N } \\
09: 29\end{array}$ & Köröstej LTD. & $\begin{array}{c}\text { هنغاريا } \\
\text { Hugary }\end{array}$ & سمايل & $\begin{array}{c}\text { جبنة تثدر مطبوخة } \\
\text { Processed } \\
\text { Cheddar Cheese }\end{array}$ & $\mathrm{C}_{14}$ \\
\hline مذكورة & $\begin{array}{c}\text { العربية والإنكليزية } \\
\text { Arabic \& } \\
\text { English }\end{array}$ & 113 & $\begin{array}{c}\text { درفظ في مكان نظيف وجاف في حرارة لاتقل عن 25م } \\
\text { Store in clean, Dry area } \\
\text { below } 25 \text { C }\end{array}$ & $\begin{array}{c}28 / 08 / 2 \\
020\end{array}$ & $\begin{array}{c}29 / 08 / \\
2018\end{array}$ & 05:46 S & $\begin{array}{c}\text { Bega Cheese } \\
\text { Limited }\end{array}$ & $\begin{array}{c}\text { (ستراليا } \\
\text { Australia }\end{array}$ & $\begin{array}{c}\text { بيغ } \\
\text { Bega }\end{array}$ & $\begin{array}{c}\text { جبن مطبوخ } \\
\text { Processed } \\
\text { Cheese }\end{array}$ & $\mathbf{C}_{15}$ \\
\hline مذكورة & $\begin{array}{c}\text { العربية والإنكليزية } \\
\text { Arabic \& } \\
\text { English }\end{array}$ & 56 & $\begin{array}{c}\text { عند فتح العبة تحفظ مبردة } \\
\text { Once opened, refrigerate }\end{array}$ & $\begin{array}{c}23 / 11 / 2 \\
020\end{array}$ & $\begin{array}{c}24 / 11 / \\
2018\end{array}$ & BN.D 80:58 & $\begin{array}{c}\text { Balkan Industrial } \\
\text { Co. }\end{array}$ & $\begin{array}{c}\text { الاردن } \\
\text { Jordan }\end{array}$ & $\begin{array}{c}\text { بلقان } \\
\text { Balkan }\end{array}$ & $\begin{array}{c}\text { جبنة الشيار } \\
\text { Cheddar Cheese }\end{array}$ & $\mathbf{C}_{16}$ \\
\hline مذكورة & $\begin{array}{c}\text { العربية والإنكليزية } \\
\text { Arabic \& } \\
\text { English }\end{array}$ & 50 & $\begin{array}{c}\text { يحفظ في مكان بارد وجاف، بلفتح يحف في الثلاجة } \\
\text { Save in cool and dry } \\
\text { place, keep refrigerated } \\
\text { after opening } \\
\text { Once opened, refrigerate }\end{array}$ & $\begin{array}{c}01 / 05 / 2 \\
020\end{array}$ & $\begin{array}{c}30 / 10 / \\
2018\end{array}$ & غير واضح & $\begin{array}{c}\text { Mondelez } \\
\text { International }\end{array}$ & $\begin{array}{c}\text { البحرين } \\
\text { Bahrain }\end{array}$ & $\begin{array}{l}\text { كرافت } \\
\text { Kraft }\end{array}$ & $\begin{array}{c}\text { جبنة تثيدر مطبوخة } \\
\text { Processed } \\
\text { Cheddar Cheese }\end{array}$ & $\mathbf{C}_{17}$ \\
\hline مذكورة & $\begin{array}{c}\text { العربية والإنكليزية } \\
\text { Arabic \& } \\
\text { English }\end{array}$ & 56 & 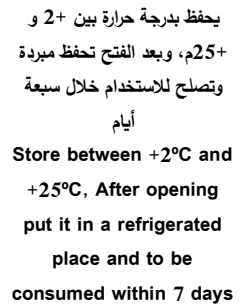 & $\begin{array}{c}03 / 02 / 2 \\
021\end{array}$ & $\begin{array}{c}04 / 02 / \\
2019\end{array}$ & $\begin{array}{r}\text { B9 } 036 \\
\text { KON N } \\
21: 27\end{array}$ & Köröstej LTD. & $\begin{array}{c}\text { هنغاريا } \\
\text { Hugary }\end{array}$ & $\begin{array}{l}\text { هاجدو } \\
\text { Hajdu }\end{array}$ & $\begin{array}{c}\text { جبنة تشيار مطبوخة ومبسرة } \\
\text { Processed and } \\
\text { Pasteurized } \\
\text { Cheddar Cheese }\end{array}$ & $\mathrm{C}_{18}$ \\
\hline مذكورة & $\begin{array}{c}\text { العربية والإنكليزية } \\
\text { Arabic \& } \\
\text { English }\end{array}$ & 113 & يحفظ في مكان بارد & $\begin{array}{c}30 / 09 / 2 \\
019\end{array}$ & $\begin{array}{c}01 / 10 / \\
2018\end{array}$ & $\begin{array}{c}\text { Art-Nr. } \\
36353 / 01- \\
15\end{array}$ & $\begin{array}{c}\text { GebrüderWoerle } \\
\text { GmbH }\end{array}$ & $\begin{array}{c}\text { النمسا } \\
\text { Austria }\end{array}$ & $\begin{array}{l}\text { البقرة السعيدة } \\
\text { Happy Cow }\end{array}$ & $\begin{array}{c}\text { جبنة نمساوية مصنعة } \\
\text { Austrian } \\
\text { Processed } \\
\text { Cheese }\end{array}$ & $\mathbf{C}_{19}$ \\
\hline مذكورة & $\begin{array}{c}\text { العربية والإنكليزية } \\
\text { Arabic \& } \\
\text { English }\end{array}$ & 380 & 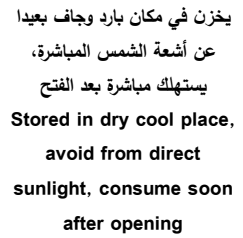 & $\begin{array}{c}19 / 03 / 2 \\
019\end{array}$ & $\begin{array}{c}19 / 09 / \\
2017\end{array}$ & $\begin{array}{l}\text { Lot No: } \\
1132 \\
3502 / 01 \\
040 \\
805 \mathrm{~B} 2\end{array}$ & $\begin{array}{l}\text { ZhangzhouXinfud } \\
\text { e Trade Co.,LTD }\end{array}$ & $\begin{array}{l}\text { الصين } \\
\text { China }\end{array}$ & $\begin{array}{l}\text { سنيوز } \\
\text { Senior }\end{array}$ & $\begin{array}{c}\text { فطر (مقطع ومسلوق) } \\
\text { Mushrooms } \\
\text { (Pieces \& Stems) }\end{array}$ & $\mathbf{C}_{20}$ \\
\hline
\end{tabular}


المجلد (12) العدد (2) (12)

2020 لسنة
المجلة العراقية

لبحوث السوق وحماية المستهملك

\begin{tabular}{|c|c|c|c|c|c|c|c|c|c|c|c|}
\hline مذكورة & $\begin{array}{c}\text { العربية والإنكليزية } \\
\text { والفرنسية } \\
\text { Arabic, } \\
\text { English \& } \\
\text { French }\end{array}$ & 125 & $\begin{array}{c}\text { يحظظ في مكان بارد وجاف } \\
\text { Keep in a cool and dry } \\
\text { place }\end{array}$ & $\begin{array}{c}26 / 12 / 2 \\
020\end{array}$ & $\begin{array}{c}27 / 12 / \\
2018\end{array}$ & $\begin{array}{c}\text { غير مذكور } \\
\text { Not found }\end{array}$ & $\begin{array}{l}\text { Atlantic } \\
\text { Conserves }\end{array}$ & $\begin{array}{c}\text { المغرب } \\
\text { Morocco }\end{array}$ & $\begin{array}{c}\text { فونتي } \\
\text { Founty }\end{array}$ & $\begin{array}{c}\text { سردين مطبوخ بالزيت } \\
\text { بالنباتي } \\
\text { Sardines in } \\
\text { Vegetable Oil }\end{array}$ & $\mathbf{C}_{21}$ \\
\hline
\end{tabular}

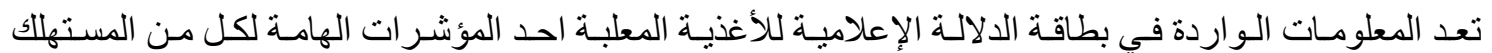

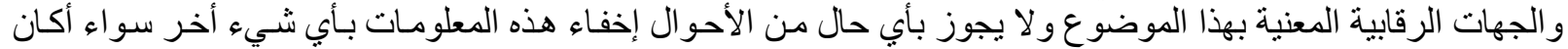

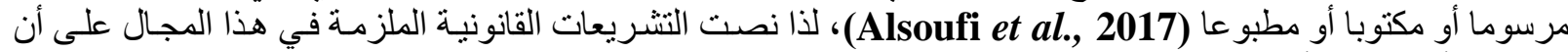

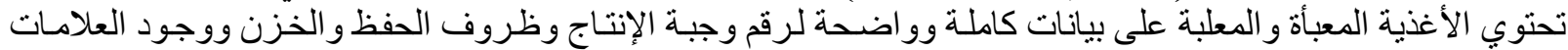

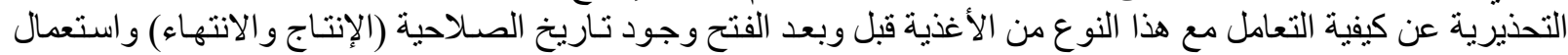

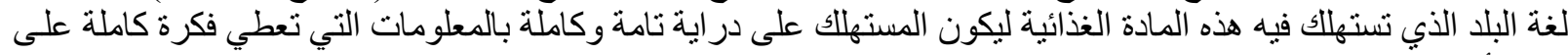

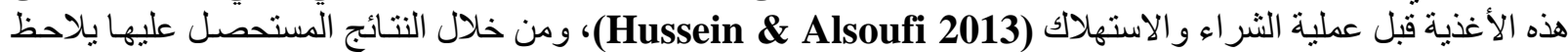

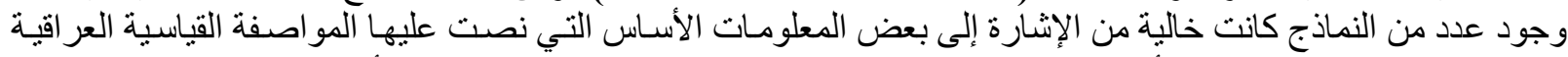

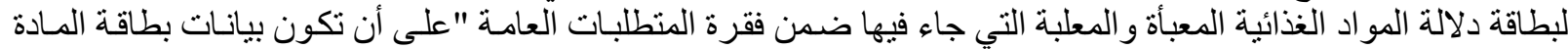

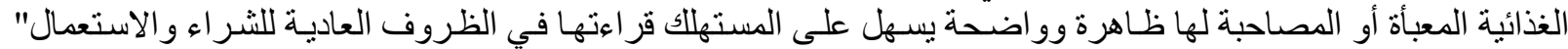

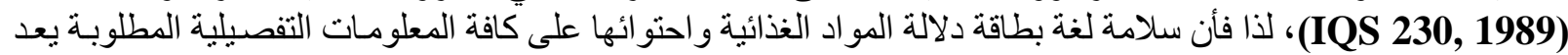

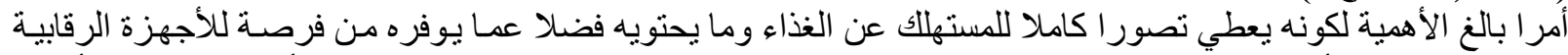

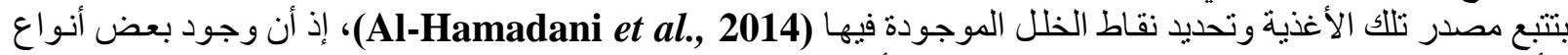

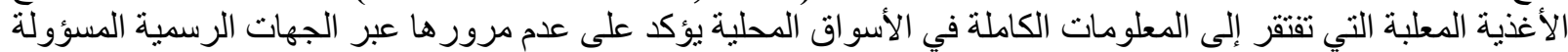

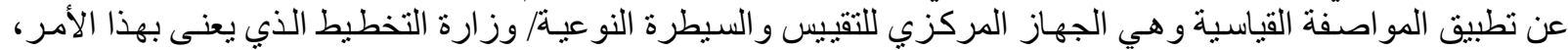

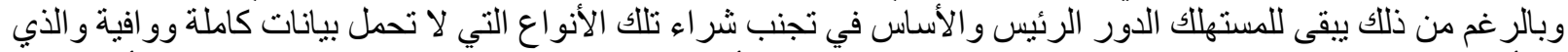

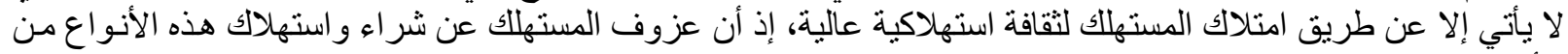

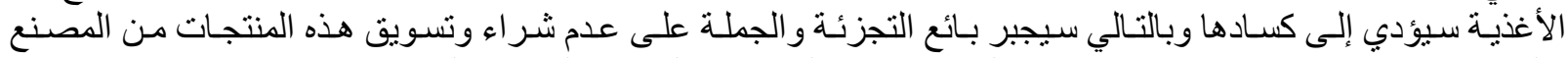

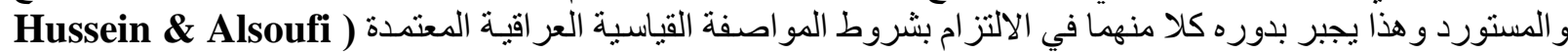

.(2013; Al-Hamadani et al., 2014; Alsoufi et al., 2017

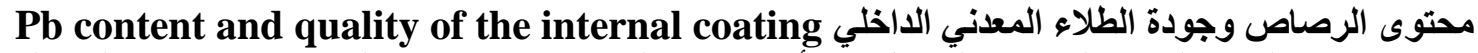

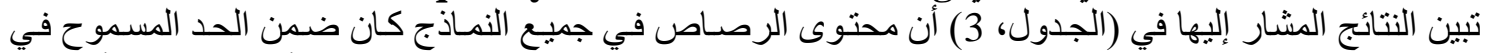

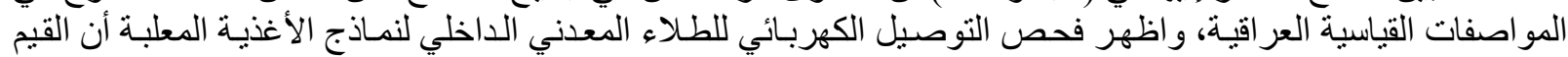

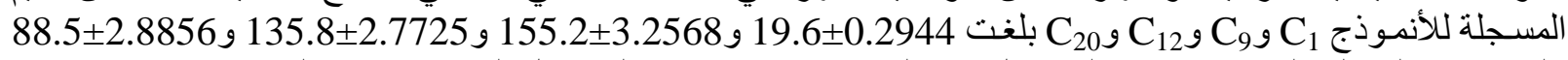

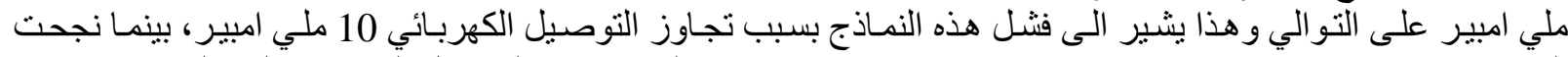
النماذج C

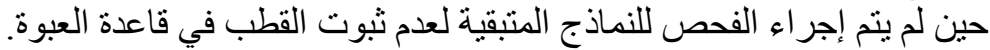

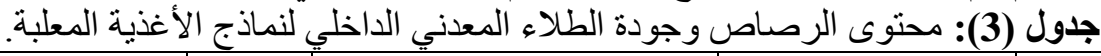

\begin{tabular}{|c|c|c|c|c|}
\hline 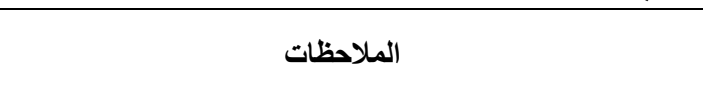 & النتيجة & $\begin{array}{c}\text { التوصيل الكهربائي (ملي أمبير) } \\
\text { (Mean } \pm \text { SD) }\end{array}$ & 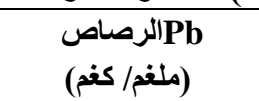 & الرمز \\
\hline تجاوز التوصيل الكهبائي 10 ملي امبير. & 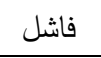 & $19.6 \pm 0.2944 \uparrow$ & $0.2648 \pm 0.0074 \downarrow$ & $\mathrm{C}_{1}$ \\
\hline \multirow{2}{*}{ 2. 1. محتوى الرصاص ضمن الكربائي لم يتجاوز 10 ملي المبير . 10 الى 5 ملغم/ كغ. } & 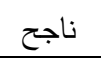 & $0.9 \pm 0.2160 \downarrow$ & $0.1874 \pm 0.0053 \downarrow$ & $\mathrm{C}_{2}$ \\
\hline & ناجح & $4.9 \pm 0.2944 \downarrow$ & $0.1739 \pm 0.0049 \downarrow$ & $\mathrm{C}_{3}$ \\
\hline محتوى الرصاص ضمن الحد المسموح 1 الى 5 ملغم/ كغم. & 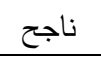 & - & $0.1814 \pm 0.0051 \downarrow$ & $\mathrm{C}_{4}$ \\
\hline \multirow{3}{*}{ 2. 1. محتوى الرصاص ضمن الكهربئي لم يتجاوز الحد المسمح 10 ملي المبير 5 ملغم/ كغم. } & ناجح & $0.8 \pm 0.2160 \downarrow$ & $0.3802 \pm 0.0107 \downarrow$ & $\mathrm{C}_{5}$ \\
\hline & ناجح & $1.1 \pm 0.2160 \downarrow$ & $0.1532 \pm 0.0043 \downarrow$ & $\mathrm{C}_{6}$ \\
\hline & ناجح & $4.2 \pm 0.2944 \downarrow$ & $0.0649 \pm 0.0018 \downarrow$ & $\mathrm{C}_{7}$ \\
\hline محتوى الرصاص ضمن الحد المسموح 1 الى 5 ملغم/ كغ. & ناجح & - & $0.3676 \pm 0.0103 \downarrow$ & $\mathrm{C}_{8}$ \\
\hline تجاوز التوصيل الكهربائي 10 ملي امبير. & 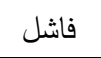 & $155.2 \pm 3.2568 \uparrow$ & $0.1279 \pm 0.0036 \downarrow$ & $\mathrm{C}_{9}$ \\
\hline
\end{tabular}


المجلد (12) العدد (2)

2020 لسنة
المجلة العراقية

لبحوث السوق ومماية المستتملك

\begin{tabular}{|c|c|c|c|c|}
\hline \multirow{2}{*}{ 2. التوصيل الكهربائي لم يتجاوز 10 ملي المبير . 1 الى 5 ملغم/ كغم. } & ناجح & $1.1 \pm 0.2160 \downarrow$ & $0.3045 \pm 0.0086 \downarrow$ & $\mathrm{C}_{10}$ \\
\hline & ناجح & $1.3 \pm 0.2160 \downarrow$ & $0.6450 \pm 0.0182 \downarrow$ & $\mathrm{C}_{11}$ \\
\hline تجاوز التوصيل الكهربائي 10 ملي امبير. & فاشل & $135.8 \pm 2.7725 \uparrow$ & $0.2162 \pm 0.0061 \downarrow$ & $\mathrm{C}_{12}$ \\
\hline \multirow{7}{*}{ محتوى الرصاص ضمن الحد المسموح 1 الى 5 ملغم/ كغم. } & ناجح & - & $0.2919 \pm 0.0082 \downarrow$ & $\mathrm{C}_{13}$ \\
\hline & ناجح & - & $0.2667 \pm 0.0075 \downarrow$ & $\mathrm{C}_{14}$ \\
\hline & ناجح & - & $0.0901 \pm 0.0025 \downarrow$ & $\mathrm{C}_{15}$ \\
\hline & ناجح & - & $0.0486 \pm 0.0014 \downarrow$ & $\mathrm{C}_{16}$ \\
\hline & 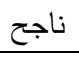 & - & $0.5820 \pm 0.0164 \downarrow$ & $\mathrm{C}_{17}$ \\
\hline & 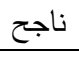 & - & $0.1153 \pm 0.0032 \downarrow$ & $\mathrm{C}_{18}$ \\
\hline & ناجح & - & $0.0018 \pm 0.0001 \downarrow$ & $\mathrm{C}_{19}$ \\
\hline تجاوز التوصيل الكهربائي 10 ملي امبير. & فاشل & $88.5 \pm 2.8856 \uparrow$ & $0.0901 \pm 0.0025 \downarrow$ & $\mathrm{C}_{20}$ \\
\hline \multirow[t]{5}{*}{ محتوى الرصاص ضمن الحد الدسموح 1 الى 5 ملغم/ كغم. } & 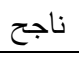 & - & $0.3423 \pm 0.0096 \downarrow$ & $\mathrm{C}_{21}$ \\
\hline & & \multicolumn{3}{|c|}{ " إذ يمثل } \\
\hline & & \multicolumn{2}{|c|}{ أعلى من القيم المسموح بها. } & $\uparrow$ \\
\hline & & \multicolumn{2}{|c|}{ أدنى أو ضمن القيم المسموح بها. } & $\downarrow$ \\
\hline & & \multicolumn{2}{|c|}{ لم يتم فحص التوصيل لعم ثبوت القطب في قاعدة العبد } & - \\
\hline
\end{tabular}

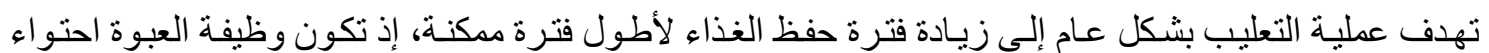

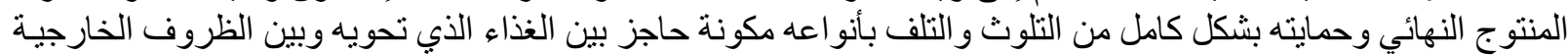

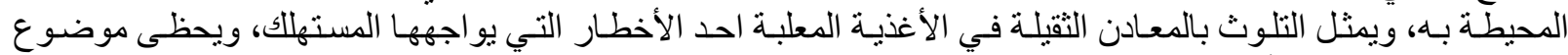

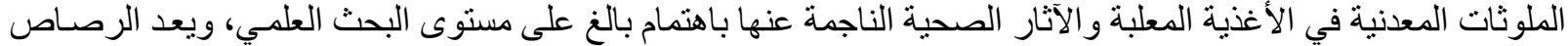

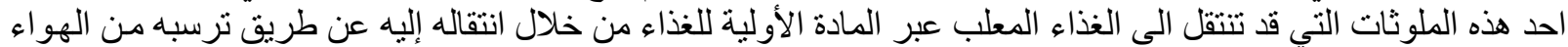

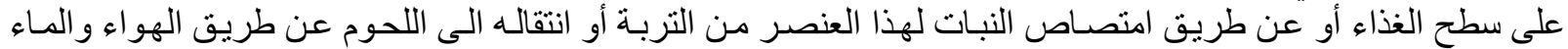

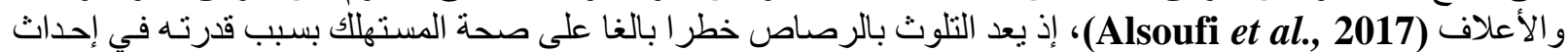

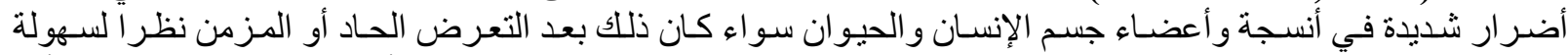

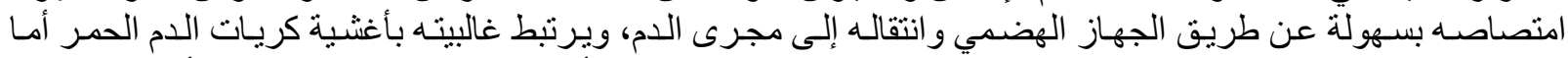

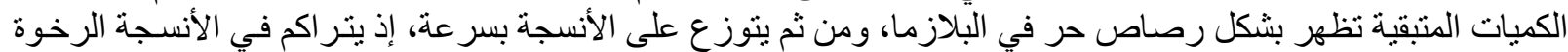

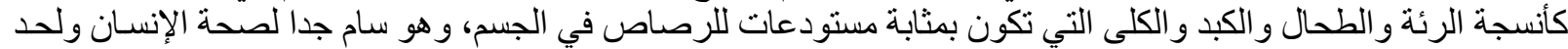

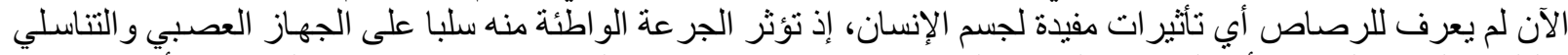

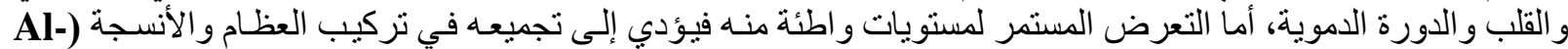
وفار (Hamadani et al., 2014

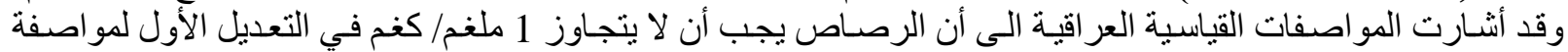

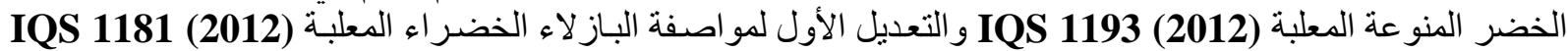

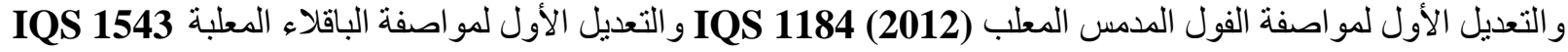

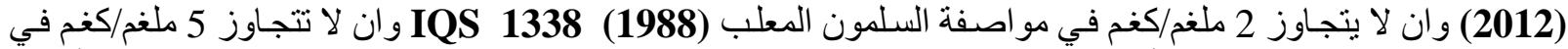

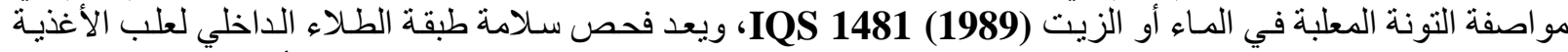

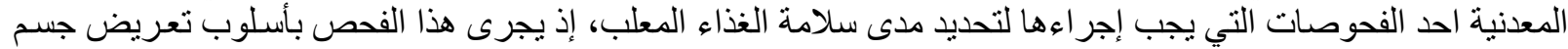

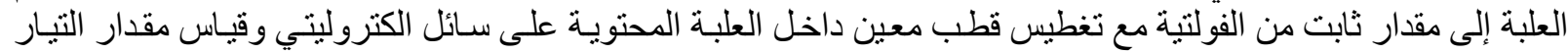

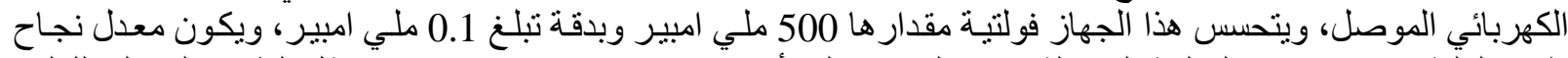

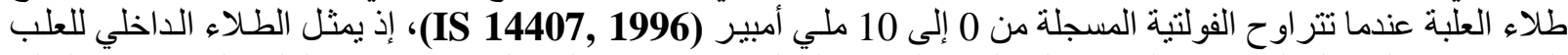

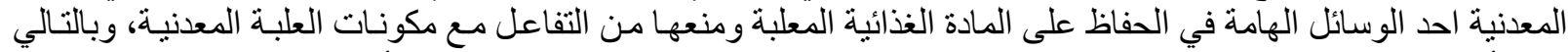

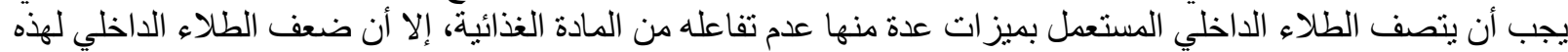

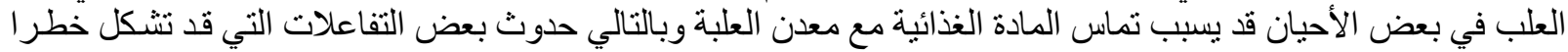


المجلد (12) العدد (2) (12)

2020 لسنة
المجلة العراقية

لبحوث السوق وحماية المستهملك

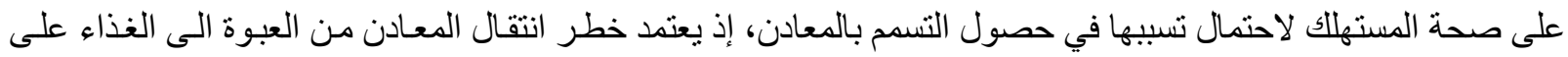

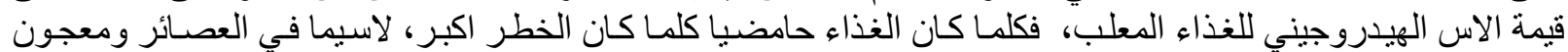

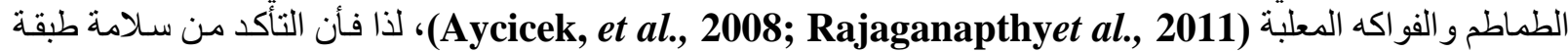

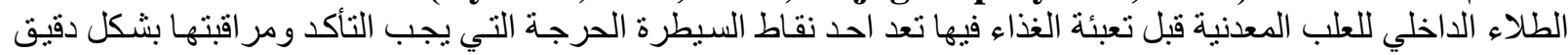

ومستمر قبل تعبئة المنتوج وتسويقه للاستهلاك لضمان جودته (ElNasriet al., 2012; Alsoufiet al., 2017).

CONCLUSIONS الاستنتاجات

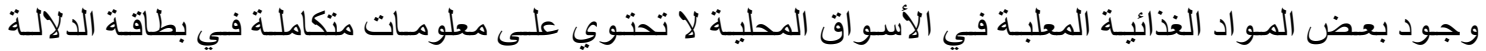

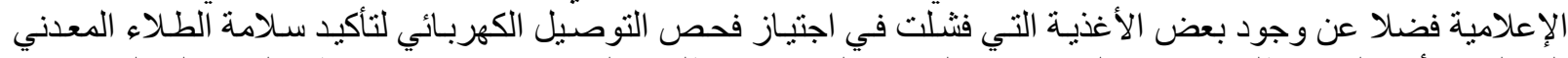

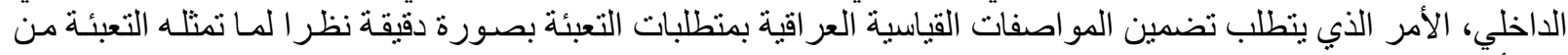

\section{REFERENCES}

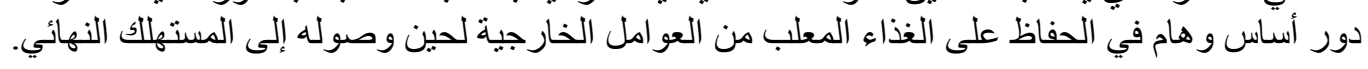

I. Abdalla, M. I., El Zubeir, I. E. Y. M. \& Hassan, F. A. (2013). Effect of packaging technique in physicochemical composition of Sudanese white soft cheese. International Journal of Scientific and Research Publications, 3(3), 1-8.

II. Al-Hamadani, H. M. S., Alsoufi, M. A. \& Ankush, J. A. (2014). Determination of some metals level in type of vegetables and fruits canned that available in locally markets. Journal of the College of Basic Education, 20(82), 273-284.

III. Alsoufi, M. A., Al-Mousawi, A. T. \& Obaid, I. H. (2017). Evaluation of the packaging efficiency of some canned foods products that available in locally markets. Thi-Qar University Journal for Agricultural Researches, 523-508.Special issue $\left(1^{\text {st }}\right.$ Scientific conference on agricultural research).

IV. Aycicek, M., Kaplan, O. \& Yaman, M. (2008). Effect of cadmium on germination, seedling growth and metal contents of sunflower (Helianthus annus L.). Asian Journal of Chemistry, 20, 2663-2672.

V. ElNasri, N. A., Sirag, S. O. \& Elsafi, H. E. H. (2012). Packaging type and their effects on the chemical and microbial quality of Sudanese white cheese (Gibnabayda). Journal of Toxicology and Environmental Health Sciences, 4(10), 185-191.

VI. Hussein, J. H. \& Alsoufi, M. A. (2013). Detection of microbial and chemical contamination in some of canned foods that available in locally markets. Tikrit Journal of Pure Science, 18(1), 135-140.

VII. IQS 1543: Iraqi Standard. (2012). Canned Beans. ${ }^{\text {st }}$ Amendment. Central Organization for Standardization and Quality Control (COSQC), Ministry of Planning, Republic of Iraq

VIII. IQS 1184: Iraqi Standard. (2012). Canned Fava Beans. $1^{\text {st }}$ Amendment. Central Organization for Standardization and Quality Control (COSQC), Ministry of Planning, Republic of Iraq

IX. IQS 1181: Iraqi Standard. (2012). Canned Green Peas. $1^{\text {st }}$ Amendment. Central Organization for Standardization and Quality Control (COSQC), Ministry of Planning, Republic of Iraq

X. IQS 1338: Iraqi Standard. (1988). Canned Salmon. Central Organization for Standardization and Quality Control (COSQC), Ministry of Planning, Republic of Iraq

XI. IQS 1481: Iraqi Standard. (1989). Canned Tuna with Water or Oil. Central Organization for Standardization and Quality Control (COSQC), Ministry of Planning, Republic of Iraq

XII. IQS 1193: Iraqi Standard. (2012). Canned Vegetables Diversified. $1^{\text {st }}$ Amendment. Central Organization for Standardization and Quality Control (COSQC), Ministry of 
المجلد (12) العدد (2) (12)

لسنة 2020
المجلة العراقية

لبحوث السوق وحماية المستهملك

Planning, Republic of Iraq

XIII. IQS 230: Iraqi Standard. (1989). Information Card of Packaged and Canned Food. Central Organization for Standardization and Quality Control (COSQC), Ministry of Planning, Republic of Iraq

XIV. IS 14407: Indian Standard. (1996). Aluminum Cans for Beverages Specification. India.

XV. Kamal, BY. (2011). The Effect of Packaging on the Purchasing Behavior of the Algerian Consumer (Travel Dairy: Blidal Case Study). MSc. Thesis. College of Economic, Business and Management Sciences. AbiBakrBelkaid University, Tlemcen. Algeria. 43.

XVI. Klevas, J., Johnsson, M. \& Jönson, G. (2012). A Packaging Redesign Project at IKEA. Lund: Department of Design Seciences, Lund University Press.

XVII. Ojha, A., Sharma, A., Sihag, M. \& Ojha, S. (2015). Food packaging materials and sustainability: A review. Agricultural Reviews, 36(3), 241-245.

XVIII. Panseri, S., Chiesa, L. M., Zecconi, A., Soncini, G. \& De Noni, I. (2014). Determination of volatile organic compounds (VOCs) from wrapping films and wrapped PDO Italian cheeses by using HS-SPME and GC/MS. Molecules, 19, 87078724.

XIX. Rajaganapthy, V., Xavier, F., Sreekumar, D. \& Mandal, P. K. (2011). Heavy metal contamination in soil, water and fodder and their presence in livestock and products: A review. Journal of Environmental Science and Technology, 4(3), 234-249.

XX. van der Berg, J. A. (2016). Identifying Packaging Criteria for Sustainable Packaging Design and Development: Towards Packaging Efficiency and Packaging Integration in the Fruit Juice Industry of South Africa. MSc Thesis. Faculty of Economic and Management Sciences, Stellenbosch University, South Africa. 